\title{
LA FISCALIDAD DEL TURISMO DESDE UNA PERSPECTIVA INTERNACIONAL
}

\author{
TAXATION OF TOURISM FROM AN INTERNATIONAL PERSPECTIVE
}

\author{
Laura Pastor Arranz \\ Universidad Rey Juan Carlos. Madrid. España/Spain \\ laura pastor arranz@,hotmail.com
}

Recibido/Received: 29/01/2015

Modificado/Modified: 02/04/2015

Aceptado/Accepted: 08/09/2015

\section{RESUMEN}

El presente artículo analiza el panorama actual de la industria turística a escala internacional destacando su importancia dentro de la economía de los países así como su carácter transversal y los efectos que provocan la coordinación de sus estrategias con las políticas de otros sectores económicos. Asimismo, se estudia la financiación pública del turismo mediante la exacción tributaria a través de los preceptos de la teoría económica de la imposición, en consonancia con los niveles óptimos de bienestar social, examinando la tributación turística internacional desde la perspectiva de los países de la OCDE, las actuaciones de la Unión Europea y el sistema fiscal español que afecta a este sector.

\section{PALABRAS CLAVE}

Actividad turística, exacción tributaria, globalización, crecimiento sostenible, administración pública.

\section{SUMARIO}

1. Introducción. 2. Panorama global del turismo. 3. La fiscalidad turística. 4. La fiscalidad sobre el turismo en la OCDE. 5. Actuaciones de la Unión Europea en referencia a la fiscalidad turística. 6. El caso de España. 7. Conclusiones. Bibliografía.

\begin{abstract}
This article analyzes the current situation of the international tourism industry highlighting its importance in the economy of the countries and its cross-cutting nature as well as the effects caused by the coordination of its strategies with the policies of the other economic sectors. Furthermore, public funding of tourism is studied by tax levy through the precepts of the economic theory of taxation, consistent with optimal levels of social welfare, examining the international tourism taxation from the perspective of OECD countries, proceedings of the European Union and the Spanish tax system concerning this sector.
\end{abstract}

\section{KEYWORDS}

Tourism, tax levy, globalization, sustainable growth, public administration.

\section{CONTENTS}

1. Introduction. 2. Global overview of tourism. 3. The tourism taxation. 4. Tourism taxation in the OECD. 5. Proceedings of the European Union in reference to the tourism taxation. 6. The case of Spain. 7. Conclusions. References. 


\section{INTRODUCCIÓN}

En este trabajo se pretende subrayar la importancia de la actividad turística en un contexto de continua globalización -derivado de la liberalización de los mercados y de la libertad de circulación- que facilita la movilidad de flujos turísticos.

Asimismo, se demostrará la relevancia de este sector en la economía mundial y el esfuerzo de acción conjunta de los gobiernos para aumentar la creación de valor a través del sector turístico.

Por otra parte, el turismo, como actividad económica, también es objeto de la fiscalidad. En los últimos apartados, se hará referencia a la fiscalidad turística desde una perspectiva comparada atendiendo a lo estipulado por la OCDE, por la Unión Europea y, más concretamente, por España.

Para el desarrollo de este estudio, se ha partido de una investigación exploratoria -teniendo en cuenta los objetivos planteados-, para conocer el estado actual del tema principal. Posteriormente, para analizarlo, se ha utilizado una metodología propia de la interdisciplinariedad científica entre el turismo, la economía y la fiscalidad.

\section{PANORAMA GLOBAL DEL TURISMO}

A tenor de la definición de la Organización Mundial del Turismo (OMT, 1994), "el turismo comprende las actividades que realizan las personas durante sus viajes y estancias en lugares distintos a su entorno habitual, por un periodo de tiempo consecutivo inferior a un año, con fines de ocio, por negocios y otros."

Hoy en día, el turismo es punto de mira de dos fenómenos relevantes: por un lado, la progresiva globalización $\mathrm{y}$, por otro, el considerable acrecentamiento y rigor de la protección medioambiental.

Respecto a este último fenómeno, la Agenda 21 (programa de acción aprobado en la Conferencia de las Naciones Unidas para el Medio Ambiente y el Desarrollo que se celebró en Río de Janeiro en el año 1992) establece la necesidad de que los países suscriptores promuevan programas de turismo ecológicamente racionales y culturalmente procedentes, integrados en el desarrollo económico y social en el horizonte del siglo XXI.

Al mismo tiempo, las estrategias de este sector se tornan cada vez más complejas ya que el turismo influye en una amplia gama de políticas nacionales como el transporte, el fomento de los servicios aéreos, las infraestructuras, la seguridad para el visitante, la energía sostenible y el incremento de la difusión de las TICs dentro de las pequeñas empresas, entre otras y, a la vez, se ve influido por ellas, resultando un clúster de servicios que no son competencia de un único sector.

Y es así que, del turismo, se obtienen efectos directos a través de los bienes y servicios suministrados a los visitantes $\mathrm{y}$, efectos indirectos, que se producen por el arrastre multiplicador que la actividad de las empresas específicamente turísticas provoca sobre las restantes empresas del sistema económico.

Consecuencia de este carácter transversal, el turismo estimula la economía creando empleo, atrayendo inversión extranjera y divisas, así como añadiendo valor a nivel local, regional y nacional. 
Por ende, una política de turismo efectiva requiere la integración de las perspectivas medioambiental, económica y social, y la necesidad de que varios ministerios y actores gubernamentales trabajen conjuntamente desde el gobierno central (OCDE, 2012: 16).

Un enfoque completo de una política turística implica la coordinación, tanto vertical como horizontal, a través de varios niveles y departamentos gubernamentales con objetivos y estrategias comunes. No obstante, en algunos países la plena competencia sobre el turismo no recae en el gobierno central sino a nivel regional permitiéndoles un acercamiento a los agentes privados y a las idiosincrasias locales.

Es un hecho que los gobiernos de los distintos países reparan en la conveniencia del turismo por su relevancia económica. Para cuantificar la importancia de la actividad turística a escala mundial, basta con acudir a los datos de la Organización Mundial del Turismo (en adelante, OMT). Según esta organización, los resultados del turismo internacional en 2013 sobrepasaron las expectativas logrando sortear las dificultades económicas, y las llegadas de turistas internacionales crecieron un 5\% hasta alcanzar los 1.087 millones (OMT, 2014: 4-6). Este aumento -con la misma tendencia progresiva en 2014, aunque a día de hoy el barómetro de la OMT no ha publicado los datos exactos del año- refleja el impacto del mayor apoyo público al sector así como la gran capacidad de adaptación a los mercados cambiantes por parte de las empresas turísticas.

La demanda de turismo internacional, en 2013, fue mayor para los destinos de Asia y el Pacífico (+6\%), África (+6\%) y Europa (+5\%). Las subregiones que más destacaron fueron el Sureste Asiático $(+10 \%)$, la Europa Central y del Este $(+7 \%)$, la Europa Meridional y Mediterránea $(+6 \%)$ y el Norte de África $(+6 \%)$. En América, el mayor crecimiento tuvo lugar en los destinos de América del Norte y América Central, mientras que América del Sur y el Caribe mostraron cierta ralentización en comparación con el año anterior (OMT, 2014).

Desde el punto de vista de emisión de turistas, los mercados más importantes del mundo, son Rusia y China. Otros mercados emergentes con un crecimiento sustancial del gasto del turismo emisor fueron Turquía $(+24 \%)$, Qatar $(+18 \%)$, Filipinas $(+18 \%)$, Kuwait $(+15 \%)$, Indonesia (+15\%), Ucrania (+15\%) y Brasil (+14\%) (OMT, 2014).

La OMT, en el análisis que realiza en Tourism 2020 Vision, prevé que las llegadas internacionales se acerquen al 1.6 billones en 2020, continuando, por tanto, la senda alcista de este sector.

Gráfico 1: Evolución de los flujos turísticos desde 1950 hasta 2020.

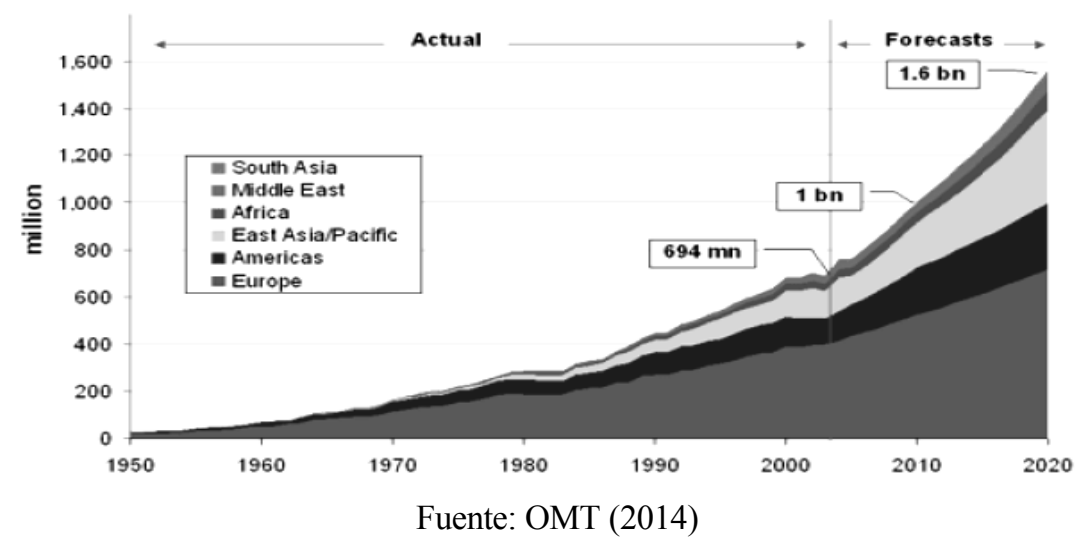


En el ámbito de los países desarrollados de la OCDE, la actividad turística, representa el $4,7 \%$ del PIB, el $21 \%$ de la exportación de servicios, el $6 \%$ del empleo, y constituye más de la mitad de las llegadas de turistas internacionales (7\%) y de los gastos (54\%) (OCDE; 2014).

No obstante, a pesar de estas favorables estadísticas, los países y los operadores tienen que adecuarse con premura a las nuevas realidades de un mercado cambiante tanto en aspectos demográficos (envejecimiento de la población, aumento de turistas de países emergentes y poblaciones en crecimiento en Asia y América, entre otros) como en las pautas de viaje y en los avances tecnológicos para atraer turistas extranjeros.

Desde el contexto español, el turismo ha sido uno de los principales factores impulsores del crecimiento económico en los últimos cincuenta años y no cabe duda de que la industria turística prosigue siendo una actividad clave e insustituible para la economía española (Cuadrado y López morales, 2011: 2). Representa casi el 11\% del PIB y el 11,8\% del empleo.

España dispone de una fortaleza y de un liderazgo indiscutido en materia turística amparado en un sector empresarial que goza de una larga experiencia competitiva. Este conjunto empresarial está caracterizado por la prevalencia de pequeñas y medianas empresas - en 2010, el 98\% del sector contaba con menos de 250 empleados y, dentro de dicho grupo, las microempresas hoteleras (hasta 9 asalariados) representaban el $79 \%$ del total $^{-}$ aunque algunos sectores, como el de la aviación, son dominados por grandes compañías a escala global.

El modelo turístico español ha disfrutado de una indudable reciedumbre, apoyando en el crecimiento ilimitado e indiscriminado de la oferta de alojamiento, el gran atractivo para la demanda internacional (mezcla de una relación bajo precio-calidad alta, unas ventajas comparativas estáticas de excelencia y una hospitalidad innata muy valorada en los principales mercados de origen) y la alta rentabilidad para las inversiones (consecuencia de reducidos costes salariales y fiscales y de la externalización de la mayor parte de los costes ambientales y sociales) (Pulido, 2011: 38).

$\mathrm{Al}$ mismo tiempo, en concordancia con la tendencia globalizadora a la que asistimos hoy en día, algunos grupos hoteleros españoles han desarrollado un proceso de internacionalización, tomando posiciones en otros mercados que son ahora competidores, o impulsando el desarrollo de nuevos mercados turísticos en algunos países emergentes.

En la actualidad, el organismo autónomo TURESPAÑA se encarga de la promoción de nuestro país como destino turístico en el exterior en colaboración con las Comunidades Autónomas, los entes locales y el sector privado, del apoyo a las empresas turísticas en el exterior, así como de las relaciones y cooperación turística internacionales.

Por otra parte, la Secretaría de Estado de Turismo aprobó el Plan Nacional e Integral de Turismo. En él se recoge una serie de directrices estatales para el período 2012-2015, cuya finalidad es impulsar la competitividad del sector turístico español, renovando al tiempo el liderazgo mundial en este campo de actividad. Entre las medidas del Plan Nacional e Integral de Turismo, se propone el establecimiento de bonificaciones en las tarifas aeroportuarias para desestacionalizar la demanda; optimización en la expedición de los visados turísticos; apoyo a los municipios turísticos; fomento del turismo sostenible con el medio ambiente y apoyo a la internacionalización de las empresas turísticas (Turespaña, 2012).

Sin embargo, a pesar de la solidez de esta industria, el actual modelo turístico español adolece de dificultades relativas a los problemas financieros de los municipios españoles para hacer frente a un creciente volumen de competencias que no va acompasado de una mayor capacidad financiera. Este problema es incuestionable respecto a los municipios turísticos, que se ven compelidos a asumir la prestación de nuevos servicios para atender a unas necesidades y expectativas crecientes por parte de una demanda más exigente. No hay 
que olvidar que la incapacidad de los municipios para responder adecuadamente la provisión de los bienes y/o servicios públicos que conforman el producto turístico repercute de manera directa en la satisfacción del turista, en el atractivo del destino $\mathrm{y}$, en definitiva, en su capacidad competitiva.

\section{LA FISCALIDAD TURÍSTICA}

La actividad turística debe ser regulada públicamente para maximizar el beneficio social neto en el tiempo. Es en este punto, y de acuerdo con Max Weber, donde debe verificarse la legitimidad del cumplimiento de la Administración, y en consecuencia de la política fiscal, en base a los principios de neutralidad, independencia y fiabilidad (Weber, 1993: 20).

Dentro de las políticas públicas sobre el sector turístico, la tributación juega un papel significativo. En primer lugar, por la magnitud de la recaudación potencial en términos de sistema fiscal y su elevada aceptabilidad social. En segundo lugar, por su capacidad de actuar como sustituto de un precio de bienes y servicios públicos consumidos por los turistas. Y, finalmente, por el papel corrector del que se puede dotar a estos últimos (Gago et al. 2004: 105).

Se añade que la fiscalidad repercute en el poder adquisitivo, las formas de vida, de integración, de movilidad y de solidaridad social de los distintos países (Durkheim, 1974: 36).

La OMT ha definido la fiscalidad turística como "aquellos tributos que se aplican específicamente a la industria del turismo o, alternativamente si no se aplican específicamente al sector turístico, aquéllos que se aplican a finalidades distintas relacionadas con esa industria."

Por tanto, el turismo como actividad económica no escapa de la fiscalidad. La variedad e intensidad de estas actuaciones tributarias responde a tres razones (Gago et al. 2004: 106-107):

- Objetivos recaudatorios: los gobiernos expanden la presión fiscal sobre el turismo por encima de la media, por sus reducidos efectos distorsionantes y por la exportabilidad de la carga fiscal.

- Cobertura de costes convencionales que ocasionan los turistas en la provisión de bienes y servicios públicos. El tributo actuaría aquí como un precio teóricamente guiado por el principio del beneficio y, de no cubrir el citado sobrecoste, se ocasionaría una carga extra a los contribuyentes no turistas.

- Internacionalización de costes externos. Básicamente los costes ambientales y de congestión como son, por ejemplo, la degradación visual, natural y de ecosistemas a causa de una construcción excesiva, la fragmentación de ecosistemas, la degeneración de la calidad del mar por exceso de residuos humanos o sobresaturación o la contaminación acústica. Si un impuesto incluye los costes ambientales y de congestión en el precio final del paquete turístico, a modo de tributo pigouviano, producirá una restauración de la eficiencia económica.

Por su parte, Gooroochurn y Sinclair (2005: 479), en su estudio sobre la fiscalidad turística, establecen que los impuestos pueden llegar a ser ineficaces e inequitativos si no se establecen los niveles óptimos de maximización del bienestar. Claramente, la fiscalidad turística se ha convertido en un tema polémico y, dada su creciente importancia en los países desarrollados y en desarrollo, es necesaria una mayor comprensión de sus fundamentos económicos y los efectos que se derivan de los mismos.

Tradicionalmente, la actividad turística ha sido objeto imponible bajo una dilatada amalgama de figuras tributarias: impuestos directos sobre las industrias (impuesto sobre la 
renta societaria), indirectos sobre los consumos turísticos (impuesto sobre el valor añadido), impuestos ambientales, tributos de acceso (tasas por entrada y salida del país o visados), etc. De hecho, la realidad muestra que un sector tradicionalmente beneficiario de una baja presión fiscal se está convirtiendo en objetivo prioritario para los sistemas fiscales de muchos países (OMT, 1998).

En los últimos años se ha producido un aumento generalizado de los impuestos, tarifas y cargos vinculados al sector del turismo, incluidos los orientados al cuidado del medio ambiente.

A continuación, basándome en las clasificaciones de la OMT y de Gooroochurn y Sinclair (2005), se compendian las clases de tributos que afectan, de manera directa e indirecta, a la actividad turística:

- Tributos sobre entradas y salidas: impuestos sobre entradas y salidas, visados, derechos aduaneros.

- Imposición sobre el transporte aéreo: impuesto sobre el carburante, tasas aeroportuarias, tributos de entrada/tránsito/salida, tasas de seguridad.

- Imposición sobre el transporte terrestre: impuesto sobre vehículos turismos, tributos de entrada/tránsito/salida, impuesto sobre el carburante, impuesto sobre el valor añadido por transporte de pasajeros, alquiler de vehículos por los turistas, transporte por tren.

- Imposición sobre el transporte marítimo: impuesto sobre el carburante, tributos de entrada/tránsito/salida, tasas de seguridad.

- Tributos sobre las agencias de viajes, touroperadores y guías de turismo.

- Tributación sobre el alojamiento: pernoctación, cama, impuesto sobre el valor añadido, impuesto sobre ventas y prestación de servicios.

- Tributación sobre restaurantes: impuesto sobre el valor añadido e impuestos especiales.

- Tributación sobre atractivos turísticos y culturales: acceso a museos, teatros, conciertos, parques naturales, actividades deportivas, parques de atracciones.

- Tributos sobre el juego: tributos sobre casinos, bingos y juegos de azar.

- Tributación sobre la formación de personal: costes a la Seguridad Social, impuesto sobre la renta de las personas físicas, impuesto sobre la renta de las personas jurídicas, impuesto sobre el volumen de negocio.

- Tributos relacionados con el medio ambiente.

Dentro de los tributos ambientales aplicables sobre el sector turístico, cabría diferenciar entre las figuras concretas que afectarían específicamente a turistas (sobre el uso de vehículos de alquiler, sobre el acceso a zonas naturales de recreo, etc.) y aquéllas aplicadas con generalidad y que, consecuentemente, también gravarían los consumos turísticos (sobre las emisiones de $\mathrm{CO} 2$, dióxido de carbono, a modo de ilustración). En ambos casos es básico que la aplicación de estos instrumentos fiscales lleve a unos efectos ambientales positivos por el lado del ingreso, esto es, que exista un buen vínculo entre el hecho imponible gravado y el problema ambiental a controlar (Gago y Labandeira, 2001).

Este tipo de solución se recoge explícitamente en el principio quien contamina paga. Esta vía fue propuesta por Pigou, quien suponía que las externalidades eran un fallo de mercado que debía ser corregido mediante un sistema impositivo. En su forma más pura, el tributo pigouviano consiste en un impuesto por unidad productiva, calculado de forma que su importe coincide con el valor de la externalidad evaluada en el punto óptimo. En definitiva, la utilización de los tributos ambientales para corregir el daño ambiental, tiene como objetivo cambiar comportamientos y no tanto recaudar dinero (Macadán, 2006: 63).

No obstante lo anterior, si bien los gobiernos obtienen de los tributos turísticos los recursos para apoyar la inversión pública, también deberían contemplar que una minoración de los 
impuestos podría contribuir a impulsar el crecimiento del turismo y a motivar el gasto de los visitantes, vía tasas reducidas orientadas a los hoteles y restaurantes y a la devolución del impuesto sobre el valor añadido.

\section{LA FISCALIDAD SOBRE EL TURISMO EN LA OCDE}

Los países de la OCDE lideran el turismo mundial siendo, a su vez, el turismo nacional de primordial importancia para la economía de esta industria. El turismo nacional e internacional sumados, son capaces de sustentar el empleo y añadir valor local. Las políticas públicas activas sobre turismo resultan fundamentales para que las economías más adelantadas en esta área prosperen en la economía turística mundial.

En 2014, la OCDE ha publicado el informe OECD Tourism Trends and Policies mediante el cual analiza el desarrollo de las últimas políticas de turismo destacables, entre ellas, la fiscalidad del turismo, es decir, aquellos tributos aplicables específicamente a los turistas, al sector turístico y a los destinos turísticos. Pero para entender su creciente trascendencia, se requiere que los interesados entiendan sus beneficios e impactos potenciales. La OCDE considera que es una de las herramientas más relevantes para proveer inversión suficiente para infraestructuras y servicios, generar empleo así como para el apoyo a la promoción de las actividades turísticas dentro de un contexto de competitividad en aras de apoyar el crecimiento sostenible a largo plazo de la industria turística.

En este informe, se examinan las últimas tendencias en fiscalidad turística destacando las siguientes afirmaciones: en los últimos quince años han aumentado los tributos turísticos, en concreto, los relativos al transporte aéreo; la mayoría de los impuestos referentes a hoteles y hospedaje se gestionan por las municipalidades; los tipos impositivos reducidos se centran principalmente en alojamiento y, algunos, en restaurantes; se ha acrecentado la exacción medioambiental conducente a una mejora del comportamiento de los agentes y turistas, o destinados a un fondo para mitigar los impactos del turismo en el medio ambiente; no obstante, se han mantenido e introducido incentivos fiscales para la inversión en hoteles y otras instalaciones de ocio para así incrementar el gasto de los turistas y promover el turismo nacional.

Sin embargo, este estudio colige que de la fiscalidad no sólo subyace una finalidad recaudatoria (OCDE, 2014: 73-74) sino que también tiene por objeto: a) la protección medioambiental a través, por ejemplo, del impuesto sobre alojamiento (tax accommodation) de Islandia cuyos ingresos se destinan al Fondo de Protección del Sitio Turístico (Tourist Site Protection Fund) para el desarrollo, mantenimiento y protección de la naturaleza; b) la recuperación del coste del procesamiento de las entradas en los puertos, como en Sudáfrica; c) la seguridad de los viajeros, tal y como en Nueva Zelanda utilizan las tasas de protección de los pasajeros (passenger security charges); d) el fortalecimiento de la creación de empleo y la acentuación del gasto del visitante mediante la devolución del impuesto sobre el valor añadido o mediante tasas reducidas en hoteles y restaurantes; e) la promoción y el marketing del turismo como, en particular, con la afectación del 80\% de los ingresos del impuesto sobre los no inmigrantes que grava la entrada al país de personas con intereses turísticos en México; f) el desarrollo de la inversión en infraestructura, en concreto, Australia lo consigue a través del tratamiento fiscal favorable para hoteles (concessional tax treatment for hotels).

En base a estas finalidades, la OCDE, en su Informe de 2014, establece seis categorías de tributación turística: 
a) Llegadas y salidas: incluye aquellos tributos que recaen con carácter general sobre los individuos pero, en ocasiones, también sobre los agentes y/o tripulación cuando entran o salen de un país por cualquier medio de transporte. Normalmente están afectos a los costes administrativos asociados a aduanas, inmigración, tratamiento de pasajeros, la expedición de visados incluso a la promoción y marketing de actividades turísticas. Véanse en Australia las tasas de visados (Electrionic Travel Authority o la Visitor Tourist Stream) que autorizan a los visitantes a entrar y viajar por el país, los impuestos de embarque en Chile, el visado en Israel para cubrir el coste que requiere el proceso de expedición de visados y los cargos de Nueva Zelanda (visitor visa fee) o Sudáfrica.

b) Transporte aéreo: atiende a dos objetivos, en primer lugar, para hacer frente al coste del servicio, como con el cargo aeroportuario sobre los pasajeros de vuelos internacionales de Estonia, o con el impuesto sobre el pasajero en Grecia que financia los costes de operatividad y los de inversión de los aeropuertos griegos y, en segundo lugar, para promocionar un comportamiento amigable con el medio ambiente como con la exacción al transporte aéreo en las salidas de pasajeros de los aeropuertos austriacos con ciertas excepciones (air transport levy) o, en Alemania, con el impuesto sobre el billete aéreo.

c) Hoteles y alojamiento: la gran mayoría gestionados desde un punto de vista subnacional salvo en Chile, la República Checa, Egipto, Irlanda y España cuya gestión también se realiza desde un punto de vista nacional.

d) Tipos impositivos reducidos sobre el consumo: que comprenden tanto los impuestos sobre el valor añadido como los impuestos sobre bienes y servicios, y representan la principal fuente de ingresos de los países de la OCDE. Las tipos impositivos varían considerablemente de un país a otro. De hecho, no todos los países miembros tienen tasas reducidas sobre los hoteles (en Israel y en México el tipo es $0 \%$ ) y no todos contemplan tipos impositivos reducidos sobre los restaurantes (ver Tabla 1).

e) Medio ambiente: para fomentar la inversión en destinos ecológicos e infraestructuras, equipos o tecnología tendentes a reducir la basura, fomentar la eficiencia de la energía y el agua, la conservación de la biodiversidad y fortalecer los nexos con los negocios locales y las organizaciones. En Australia, obligan al pago de una tasa para acceder al Parque Marino Gran Barrera del Coral y, en Egipto, se exigen ecotributos en 12 zonas protegidas. En Francia, cuentan con el impuesto sobre el ruido aéreo. Y en Portugal, aprobaron el impuesto para la certificación de eficiencia energética y calidad del aire para las empresas turísticas.

f) Incentivos: como vacaciones fiscales, deducciones por inversión, tipos reducidos del impuesto sobre sociedades, incentivos basados en la localización, exenciones y zonas especiales económicas. En Dinamarca, los propietarios de casas vacacionales disfrutan de una deducción sobre los ingresos derivados del alquiler de estos inmuebles. En Francia, aprobaron una deducción del 50\% de los gastos para los maestros chefs. Y en Polonia, el rendimiento derivado del alquiler de habitaciones a huéspedes en zonas rurales está exento del impuesto sobre la renta.

\section{ACTUACIONES DE LA UNIÓN EUROPEA EN REFERENCIA A LA FISCALIDAD TURÍSTICA}

Europa es el primer destino turístico del mundo, con la mayor densidad y diversidad de atractivos para el visitante. Por ello, la industria del turismo se ha convertido en un sector clave de la economía europea que genera, directa o indirectamente, más del 10\% del PIB de la UE y da empleo a 9,7 millones de trabajadores en 1,8 millones de empresas. El turismo 
contribuye a aspectos tales como el empleo y el desarrollo regional (política de cohesión para 2007-2013), el desarrollo sostenible, la mejora del patrimonio natural y cultural y la configuración de la identidad europea.

Tabla 1: Tipos impositivos sobre el consumo en países de la OCDE.

\begin{tabular}{|l|c|c|c|}
\hline \multirow{2}{*}{ País de la OCDE } & Tipo impositivo & \multicolumn{2}{|c|}{ Tipo reducido (\%) } \\
\cline { 3 - 4 } & General (\%) & Hoteles & Restaurantes \\
\hline Australia & 10 & $\ldots$ & $\ldots$ \\
\hline Austria & 20 & 10 & 10 \\
\hline Bélgica & 21 & 6 & 12 \\
\hline Canadá & 5 & $\ldots$ & $\ldots$ \\
\hline República Checa & 21 & 15 & $\ldots$ \\
\hline Finlandia & 24 & 10 & 14 \\
\hline Francia & 19,6 & 7 & 7 \\
\hline Alemania & 19 & 7 & $\ldots$ \\
\hline Grecia & 23 & 6,5 & 13 \\
\hline Hungría & 27 & 18 & $\ldots$ \\
\hline Islandia & 25,5 & 7 & 7 \\
\hline Israel & 18 & 0 & $\ldots$ \\
\hline Irlanda & 23 & 9 & 9 \\
\hline Italia & 21 & 10 & 10 \\
\hline Japón & 5 & $\ldots$ & $\ldots$ \\
\hline Corea & 10 & $\ldots$ & $\ldots$ \\
\hline Luxemburgo & 15 & 3 & 3 \\
\hline México & 16 & 0 & $\ldots$ \\
\hline Noruega & 25 & 8 & 15 \\
\hline Polonia & 23 & 8 & 8 \\
\hline Portugal & 23 & 6 & $\ldots$ \\
\hline Suecia & 25 & 12 & 12 \\
\hline España & 21 & 10 & 10 \\
\hline & & & \\
\hline
\end{tabular}

Fuente: OCDE y Comisión Europea (2014)

Dentro de las estrategias de la Unión Europea que afectan a la fiscalidad turística, resaltar la política común para la expedición de visados para aquellos ciudadanos no europeos que vayan a viajar por el espacio Schengen. Por otra parte, subrayar que todos los Estados Miembros tienen marco normativo común sobre el IVA en base a la Directiva 2006/112/CE en virtud de la cual los Estados deberán establecer un tipo impositivo común que no podrá ser inferior al $15 \%$ y, además, los Estados Miembros podrán aplicar uno o dos tipos reducidos (que no podrán ser inferiores al 5\%) a las entregas de bienes y prestaciones de servicios de las categorías que figuran en el anexo III de esta Directiva. En este anexo, se delimitan actividades relacionadas con la industria turística, entre ellas, el transporte de personas y de sus equipajes; el acceso a espectáculos, teatros, circos, ferias, parques de atracciones, conciertos, museos, parques zoológicos, salas cinematográficas, exposiciones y otras manifestaciones y locales semejantes de carácter cultural; el alojamiento facilitado por hoteles y establecimientos afines, incluido el alojamiento para vacaciones y el arrendamiento de emplazamientos en terrenos para campings y espacios de estacionamiento de caravanas; los servicios de restauración y catering, con posibilidad de excluir la entrega de bebidas. 
Con estas actuaciones, la Unión europea pretende promover la industria turística de la cual se obtienen beneficios colaterales.

\section{EL CASO DE ESPAÑA}

El turismo es un importante motor de la economía, si bien provoca algunos desequilibrios financieros en los entes públicos que tienen que afrontar ciertos gastos relacionados.

En España, desde la perspectiva gubernamental, la Administración General del Estado tiene atribuidas las relaciones internacionales, la promoción y comercialización del turismo en el exterior, el diseño de la política turística general (desarrollo, cooperación,...) y la coordinación de la ordenación general de la actividad turística. Las Comunidades Autónomas asumen competencias sobre la promoción y ordenación del turismo en el ámbito de su propio territorio. La atribución de competencias a los Municipios y a las Provincias se desenvuelve fundamentalmente en relación con las actividades de información y promoción, lo que ha determinado la existencia de distintos órganos como los Patronatos de Turismo.

Para allegar recursos suficientes con los que financiar estas atribuciones, tanto el Estado, como las Comunidades Autónomas y los Entes Locales, van a acudir a las fuentes impositivas que incidan directamente sobre la empresa turística.

Los esfuerzos recaudatorios en el plano estatal, se manifiestan a través del Impuesto sobre el Valor Añadido, que recoge el régimen especial de Agencias de Viajes (artículos 141-147 de la Ley 37/1992) aplicable a las operaciones realizadas por las agencias de viajes y por los organizadores de circuitos turísticos cuando actúen en nombre propio respecto de los viajeros, y utilicen en la realización del viaje bienes entregados o servicios prestados por otros empresarios o profesionales. La singularidad de este régimen especial radica en el procedimiento para determinar la base imponible, que no está constituida por el importe total de la contraprestación, como es lo normal en otros regímenes, sino por el margen bruto de la Agencia de Viajes. A estos efectos, se considerará margen bruto de la agencia la diferencia entre la cantidad total cargada al cliente, excluido el Impuesto sobre el Valor Añadido que grave la operación, y el importe efectivo, impuestos incluidos, de las entregas de bienes o prestaciones de servicios que, efectuadas por otros empresarios o profesionales, sean adquiridos por la agencia para su utilización en la realización del viaje y redunden directamente en beneficio del viajero.

Igualmente, se manifiesta mediante la no sujeción al IVA del servicio de promoción turística de una determinada zona por ser una actividad desarrollada en el ejercicio de funciones y competencias públicas (Tribunal Supremo Sala 3 ${ }^{\mathrm{a}}$, sección 2a , S 14-4-2011, recurso 151/2007).

Asimismo, en base a los preceptos que derivan de la aplicación de la Directiva del IVA, se gravan al 10\% (tipo reducido) los transportes de viajeros y sus equipajes, los servicios de hostelería, acampamento y balneario, los de restaurantes y, en general, el suministro de comidas y bebidas para consumir en el acto, incluso si se confeccionan previo encargo del destinatario. Se exceptúan de lo dispuesto en el párrafo anterior, los servicios mixtos de hostelería, espectáculos, discotecas, salas de fiesta, barbacoas u otros análogos.

Pero el IVA no es el único impuesto que afecta al sector turístico desde el punto de vista estatal, pues las empresas turísticas se pueden beneficiar de las deducciones fiscales por el Impuesto sobre Sociedades (artículos 35-39 de la Ley del Impuesto sobre Sociedades), los incentivos fiscales para las empresas de reducida dimensión (artículos 101-105 de la misma ley) y las particularidades de los regímenes especiales de Canarias y de Ceuta y Melilla. 
La potestad tributaria de las Comunidades Autónomas para crear, regular, modificar y extinguir un tributo turístico es conferida por mandato constitucional. Con todo, esta potestad ha de ejecutarse conforme a determinados límites: ausencia de carga fiscal extra jurisdiccional por la cual las Comunidades Autónomas no pueden adoptar medidas tributarias más allá de su ámbito territorial, prohibición de establecimiento de barreras fiscales y prohibición de doble imposición para no mermar el ingreso de los entes locales y estatales (Torres, 2014: 14-16).

Uno de los esfuerzos realizados en la búsqueda de financiación es a través de la categoría de tributo extrafiscal, creando impuestos que inciden en la empresa turística. El precedente fue la ecotasa balear (Ley 7/2001, de 23 de abril, Ley del Impuesto sobre Estancias Turísticas de Alojamiento. Actualmente derogada) cuya recaudación se encontraba afecta a la dotación de un Fondo de rehabilitación de espacios turísticos (creado por Ley 12/1999, de 23 de diciembre, con la finalidad de financiar las actuaciones a que hace referencia el Título $\mathrm{V}$ de la Ley 7/2003 de 22 de octubre) y, además, tenía naturaleza regulatoria, al pretender modificar el modelo turístico balear en favor de un producto más selectivo y dirigido a los aspectos de calidad. En palabras de Gago y Labandeira (2001: 183), "la aplicación de esta figura permitiría actuar tanto sobre la oferta como sobre la demanda turística." En el primer caso, la mencionada afectación de los recursos posibilitaría incorporar o mejorar servicios asociados a una oferta turística moderna y de calidad (rutas de interés ecológico, paquetes multi-producto, etc.). Del mismo modo, el impuesto permitiría realizar una actuación estratégica sobre la demanda por cuanto sus efectos pueden ser significativos en los paquetes dirigidos a rentas medias-bajas, segmento del mercado que genera un menor valor añadido.

Sin embargo, la doctrina afirmó unánimemente que el impuesto balear no tenía una finalidad extrafiscal en sí misma puesto que no consideraba criterios ambientales, planteando igualmente problemas frente a la Constitución Española, la Ley Orgánica de Financiación de las Comunidades Autónomas y el Derecho comunitario. Actualmente este impuesto está derogado.

Posteriormente, Cataluña con la Ley 5/2012, de 20 de marzo, de medidas fiscales, financieras y administrativas creó el impuesto sobre las estancias en establecimientos turísticos para gravar la capacidad económica de las personas físicas que se pone de manifiesto con la estancia en los establecimientos y equipamientos turísticos situados en Cataluña. Los ingresos quedan afectados a la dotación del Fondo para el fomento del turismo para atender las finalidades que se determinan en el mismo (promoción, impulso, preservación, fomento y desarrollo de infraestructuras turísticas) (Secretaría General de Coordinación Autonómica y Local, 2014: 21).

La estructura del impuesto balear y catalán es similar con la salvedad de los supuestos de exención y que el catalán incluye como sujeto pasivo a las personas jurídicas.

En el ámbito local, el artículo 142 de la Constitución Española preceptúa que las Haciendas Locales deberán disponer de los medios suficientes para el desempeño de las funciones que la ley atribuye a las Corporaciones respectivas y se nutrirán fundamentalmente de tributos propios y de participación en los del Estado y Comunidades Autónomas. En este sentido, el Estado de Bienestar local, sólo se puede sostener con un equilibrado volumen de ingresos públicos que se ajuste a los previsibles gastos sociales (Garde, 1999: 193). La Ley Reguladora de las Haciendas Locales (RDHL), sistematiza el sistema tributario y financiero aplicable a las entidades locales recogiendo las tasas, contribuciones especiales, impuestos y recargos que pueden exigir para la prestación de servicios mínimos y complementarios (salubridad pública e higiene, transporte público, 
protección civil y seguridad ciudadana), la promoción, infraestructura y servicios con especial repercusión turística, sufragar los costes de las Oficinas de Información Turística y la defensa y restauración del patrimonio cultural, urbano, histórico, del paisaje, del entorno natural y del medio ambiente, en general.

Es evidente que los municipios turísticos tienen unos mayores gastos por habitante residente y esto les induce también a tener unos ingresos superiores que han podido obtener gracias a la flexibilidad de las fuentes de ingresos municipales. El artículo 125 del RDHL, considera municipios turísticos aquéllos que no siendo capitales de provincia o de Comunidad Autónoma, tengan una población de derecho entre 20.000 y 75.000 habitantes y su número de viviendas de segunda residencia supere al de viviendas principales.

A juzgar por Ruiz Galdón (2013: 5), el concepto de municipio turístico que se utiliza no es una definición socioeconómica, demográfica o territorial. Es, simplemente, un concepto hacendístico o financiero para delimitar la cesión de los rendimientos de ciertos impuestos y la participación en el Fondo Complementario de Financiación. Este medio de financiación se destina sólo a unos municipios que cumplen las condiciones legalmente establecidas.

$\mathrm{El}$ ingreso propio de las Haciendas Locales que contribuye con más relevancia a financiar los servicios resultantes de la presencia turística es el Impuesto sobre Bienes Inmuebles (IBI) debido al gran poder recaudatorio sobre el monto total ya que, en los municipios turísticos, hay una mayor relación de viviendas por habitante (puesto que muchos propietarios no residen de manera permanente), así como en la presencia de inmuebles residenciales de un valor catastral más elevado e, incluso, un número superior de propiedades inmobiliarias de uso no residencial per cápita, pero rigurosamente relacionadas con la actividad turística y establecidas en la normativa catastral como de ocio, hostelería, culturales, etc.

Otros tributos que se benefician del crecimiento urbanístico en estas áreas son el Impuesto sobre Construcciones, Instalaciones y Obras (ICIO), las tasas por el otorgamiento de licencias urbanísticas y el Impuesto sobre el Incremento de Valor de los Terrenos de Naturaleza Urbana que grava la transmisión de la propiedad de los terrenos por cualquier título o de la constitución o transmisión de cualquier derecho real de goce, limitativo del dominio sobre dichos terrenos.

Tampoco hay que olvidar el Impuesto sobre Actividades Económicas por el ejercicio de actividades turísticas ni el Impuesto sobre Vehículos de Tracción Mecánica.

Al mismo tiempo, para que la fiscalidad pueda jugar un papel extrafiscal incentivador de la calidad y del respeto al medio ambiente, los municipios podrán establecer bonificaciones para instalaciones sobre el aprovechamiento de la energía solar o para vehículos ecológicos (Puig, 2007: 183).

\section{CONCLUSIONES}

Una vez analizados los anteriores apartados se pueden deducir las siguientes conclusiones:

- A escala internacional, el turismo es un sector preponderante que aporta valor añadido a la economía.

- Su carácter transversal conlleva la coordinación de su planificación estratégica con las políticas de otros sectores que se ven influidos por los efectos de la industria turística.

- El papel de los gobiernos en las políticas de turismo se está transformando, al centrarse más en la competitividad, el valor del dinero y el crecimiento ecuánime. 
- Esta actividad es materia imponible bajo una amalgama tributaria pero, a su vez, la fiscalidad como instrumento administrativo proveedor de recursos debe ponerse al servicio de la política turística.

- La fiscalidad turística, además de contribuir a los ingresos tributarios, en general, y apoyar la inversión pública en el desarrollo turístico, contempla finalidades distintas como la recuperación de costes externos derivados de los procesos de atención a los turistas y la protección del medio ambiente, el fomento del gasto por parte de los visitantes, la creación de empleos así como la financiación de actividades de promoción.

\section{BIBLIOGRAFÍA}

ADAME MARTÍNEZ, F.D. (2013). "Turismo y financiación municipal: estudio sobre posibles nuevos Tributos Locales vinculados al turismo". Tributos locales, 112: 13-61.

BARÓMETRO OMT DEL TURISMO MUNDIAL desde $h$ ttp://mkt.unwto.org/es/barometer

CENCERRADO, E. y GALLEGO, J. B. (2013). Manual de derecho tributario del turismo. Valencia: Tirant Lo Blanch.

CUADRADO ROURA, J. R. y LÓPEZ MORALES, J. M. (2011). "El turismo: un sector clave en la economía española". Papeles de Economía española, 128: 2-20.

DIRECTIVA 2006/112/CE del Consejo, de 28 de noviembre de 2006 relativa al sistema común del impuesto sobre el valor añadido. DOUE, de 11 de diciembre de 2006, pp. 1-118.

DURKHEIM, E. (1974). Las reglas del método sociológico. Madrid: Morata.

FUENMAYOR, A., GRANELL, R. e HIGÓN, F. (2003). "Turismo sostenible y fiscalidad ambiental". Boletín Económico del ICE, 2757.

GAGO, A. y LABANDEIRA, X. (2001). "Turismo y fiscalidad ambiental". Papeles de Economía Española, 87: 179-186.

GAGO, A.; LABANDEIRA, X. y RODRÍGUEZ, M. (2004). "La imposición del turismo”. Mediterráneo Económico, 5: 105-117.

GARDE ROCA, J. A. (1999). "Sistema fiscal y modelo social: el alcance de las últimas reformas", en J.A. Garde Roca (ed.) Políticas sociales y Estado de Bienestar en España. Madrid : Trotta, pp. 191-221.

GOOROOCHURN, N. y SINCLAIR, T. (2005). "Economics of tourist taxation. Evidence from Mauritius". Annals of Tourism Research, 2: 478-498.

INSTITUTO DE TURISMO DE ESPAÑA TURESPAÑA (2012). Plan Nacional e Integral de Turismo 2012-2015. Madrid: Secretaría de Estado de Turismo.

LEY 5/2012, de 20 de marzo, de Medidas Fiscales, Financieras y Administrativas. BOE núm. 83, de 6 de abril de 2012, pp. 27915-28021.

LEY 7/2001, de 23 de abril, del Impuesto sobre Estancias Turísticas de Alojamiento. BOE núm. 125, de 25 de mayo de 2001, pp. 18338-18343.

LEY 27/2014, de 27 de noviembre, del Impuesto sobre Sociedades. BOE núm. 288, de 28 de noviembre de 2014, pp. 96939-97097.

LEY 37/1992, de 28 de diciembre, del Impuesto sobre el Valor Añadido. BOE núm. 312, de 29 de diciembre de 1992, pp. 44247-44305.

MACADÁN DÍAZ, M. (2006). "El Impacto de la Tributación Verde sobre el Turismo". Revista de Economía, Sociedad, Turismo y Medio Ambiente, 4: 58-89.

OECD (2014). Tourism Trends 2014. OECD Publishing.

OECD (2013). El sistema tributario, la innovación y el medio ambiente. Foro Consultivo Científico y Tecnológico.

OECD (2012). OECD Tourism Trends and Policies 2012. OECD Publishing.

ORGANIZACIÓN MUNDIAL DEL TURISMO (1998). La fiscalidad del turismo. Madrid: Publicaciones de la OMT. 
PUIG VENTOSA, I. (2010). "Incentivos a la I+D+i y a las inversiones medioambientales en el impuesto sobre sociedades". Crónica Tributaria, 135: 179-214.

PUIG VENTOSA, I. (2007). "Fiscalidad y sostenibilidad en los destinos turísticos". Estudios Turísticos, 172-173: 181-185.

PULIDO FERNÁNDEZ, J. I. (2011). "La sostenibilidad del modelo turístico español en un escenario de cambio global”. Papeles de Economía española, 128: 38-52.

REAL DECRETO LEGISLATIVO 2/2004, de 5 de marzo, por el que se aprueba el texto refundido de la Ley Reguladora de las Haciendas Locales (RDHL). BOE núm. 59, de 9 de marzo de 2004, pp. 1028410342.

RUIZ GALDÓN, J. M. (2013). Análisis del modelos de financiación de municipios turísticos en España. Evolución desde el año 2005. Madrid: Instituto de Estudios Fiscales.

SUBDIRECCIÓN GENERAL DE RELACIONES TRIBUTARIAS CON LAS HACIENDAS TERRITORIALES (2014). "Capítulo III Impuestos propios". Tributación Autonómica. Medidas 2014. Madrid: Secretaría General de Coordinación Autonómica y Local.

TORRES CHAVARRI, R. D. (2014). "Fiscalidad del turismo (reflexiones sobre el régimen fiscal de los establecimientos turísticos en las Comunidades Autónomas)". Revista Impuestos, 4/2014: 11-34.

UNWTO (2014). Tourism Highlights. Madrid: World Tourism Organization Publications.

UNWTO (1998). Tourism Taxation: Striking a Fair Deal. Madrid: World Tourism Organization Publications.

WEBER, M. (1993). Economía y sociedad. México: Fondo de Cultura Económica

\section{Breve currículo:}

\section{Laura Pastor Arranz}

Doctora por la Universidad Rey Juan Carlos. Máster en Dirección Internacional Contable y Financiera. Ponente del Tribunal Económico-Administrativo de Madrid. Académica numeraria de la Academia Iberoamericana de Escritores y Periodistas (AIDEP). Miembro de la Federación Española de Periodistas y Escritores de Turismo (FEPET). Participación en Congresos nacionales e internacionales de turismo, entre ellos, en la Mesa de Turismo de las ediciones XVII y XIX del Congreso Nacional de Sociología en Castilla-La Mancha, organizado por la Asociación Castellano-Manchega de Sociología. Autora de artículos socio-culturales, de turismo y de fiscalidad. Líneas de investigación: fiscalidad internacional y sociología. 